\title{
Genetics of a Lessepsian sprinter: the bluespotted cornetfish, Fistularia commersonii
}

\author{
Kimberly Tenggardjaja ${ }^{\mathrm{a}}$, Alexis Jackson ${ }^{\mathrm{a}}$, Frank Leon ${ }^{\mathrm{a}}$, Ernesto Azzurro ${ }^{\mathrm{b}}$, Daniel Golani ${ }^{\mathrm{c}}$ and Giacomo Bernardi $^{\mathrm{a} *}$ \\ ${ }^{a}$ Department of Ecology and Evolutionary Biology, University of California Santa Cruz, 100 Shaffer Road, Santa Cruz, CA 95060, USA; \\ ${ }^{b}$ ISPRA, Institute for Environmental Protection and Research, Sts Livorno, Piazzale dei Marmi 2, 57123 Livorno Italy; ${ }^{c}$ Department of \\ Evolution, Systematics and Ecology. The Hebrew University of Jerusalem, 91904 Jerusalem, Israel
}

(Received 11 June 2013; accepted 4 November 2013)

\begin{abstract}
Our current understanding of the mechanisms that lead to successful biological invasions is limited. Although local adaptation plays a central role in biological invasions, genetic studies have failed to produce a unified theory so far. The bluespotted cornetfish, a recent invader of the Mediterranean Sea from the Red Sea via the Suez Canal, provides an ideal case study to research the mechanisms of invasive genetics. Previous genetic work based on mitochondrial markers has shown the genetic diversity of the Mediterranean population was greatly reduced in comparison to the natural population in the Red Sea. In the current study, we expand upon these studies by adding mitochondrial and nuclear markers. Mitochondrial results confirm previous findings. The nuclear marker, however, does not show evidence of reduction in diversity. We interpret these results as either a differential dispersal capability in males and females, or the presence of selection on the invading Mediterranean population.
\end{abstract}

Keywords: Fistularia; commersonii; Lessepsian bioinvasion; Red Sea; Mediterranean

\section{Notes on contributors}

Kim Tenggardjaja is finishing her $\mathrm{PhD}$ at the University of California Santa Cruz. Her dissertation research focuses on understanding genetic connectivity in endemic damselfishes in the Hawaiian Archipelago. She is interested in using connectivity data to inform the design of networks of marine protected areas.

Alexis Jackson is currently a John A. Knauss Marine Policy Fellow with NOAA Fisheries in the Atlantic Highly Migratory Species Management Division based in Silver Spring, MD. Her research interests are related to the incorporation of genetic data into marine reserve design, fisheries management and marine policy for commercially exploited fishes.

Frank Leon is an undergraduate researcher at the University of California Santa Cruz, working on the Molecular Biology of fishes and other organisms.

Ernesto Azzurro is a researcher at the Institute for Environmental Protection and Research, Livorno, Italy. His work deals with the ecology and biology of non-indigenous fishes and with the study of current changes in Mediterranean fish diversity.

Daniel Golani is a Curator of Life Sciences at the Hebrew University of Jerusalem. His research focuses on Mediterranean and Red Sea fishes, their taxonomy, biology, ecology and zoogeography with an emphasis on Red Sea species colonizing the Mediterranean via the Suez Canal.

Giacomo Bernardi is a Professor at the University of California Santa Cruz. He works on phylogenetics, population genetics and speciation of fishes, including Lessepsian bioinvaders.

\section{Introduction}

The opening of the Suez Canal in 1869 started a process of invasion from the Red Sea into the Mediterranean. Migrating individuals were termed Lessepsian immigrants, after the Canal engineer Ferdinand de Lesseps.
This flow of marine organisms has had broad ecological impacts. Lessepsian fishes, which now comprise over 85 recorded species (Fricke et al. 2012), have probably displaced several native taxa (Golani 2010) and had detrimental effects on Mediterranean natural habitats (Sala et al. 2011). In general, the specific dynamics of biological invasions are poorly known, yet in this case the situation presents some definite advantages for scientists. The date of the opening of the invasion route is known, and at least in general terms, the geographic source of the invaders is also known: the Red Sea region. Thus, theoretical predictions seemed fairly simple. Some individuals from the Red Sea would enter the Mediterranean via the Suez Canal and later expand in the wide-open ecological niches westward in the Mediterranean. This scenario would likely predict a genetic bottleneck due to an invading subsample of the original populations, followed by a fast range expansion - a pattern that is consistent with other documented invasions (Sax et al. 2005). However, in contrast to this prediction, Red Sea and invasive Mediterranean fish populations seem to display a high genetic similarity and no evidence of genetic bottleneck (Golani \& Ritte 1999; Bucciarelli et al. 2002; Hassan et al. 2003; Hassan \& Bonhomme 2005; Azzurro et al. 2006). For these species, data showed that colonization had occurred by a large number of individuals, by multiple colonization events, or a combination of both. Importantly, all of these studies were conducted decades or even more than a century after the invasion of a particular species had occurred, thus raising the question of methodological biases.

The situation of the bluespotted cornetfish, Fistularia commersonii, is quite different. This species, which is

*Corresponding author. Email: bernardi@ucsc.edu 
naturally distributed broadly in the Indo-Pacific, was first recorded in the Mediterranean near Ashdod, Israel in January 2000 (Golani 2000). Since then it has rapidly spread westward to the southern shores of Italy, Sardinia and later France and Spain, with records in the north Aegean, Adriatic and Alboran Sea, the furthest a Lessepsian fish species has ever been recorded (Dulčić et al. 2007; Sanchez-Tocino et al. 2007; Garibaldi \& Orsi Relini 2008; Deidun \& Germanà 2011; Azzurro et al. 2012; Pirkenseer 2012). The exact beginning of colonization of a particular Lessepsian species is often difficult to determine. However, since $F$. commersonii is relatively large and elongated, a conspicuous morphology unlike any other fish in the Mediterranean, it is very likely that they were discovered a very short time after their arrival.

Genetic work on F. commersonii based on mitochondrial control regions of 101 individuals, including 52 from the Mediterranean, only revealed two haplotypes in the Mediterranean (Golani et al. 2007). These results suggested that very few individuals (possibly as few as two females) had entered the Mediterranean (Golani et al. 2007). Indeed, parasitological work suggests that adults, not larvae, are most likely to have first invaded the Mediterranean (Merella et al. 2010). More recent genetic work has expanded earlier findings and, with additional DNA sequences, the genetic diversity of the Mediterranean individuals increased. Using four mitochondrial loci and 12 individuals collected in Italy (6) and Tunisia + Libya (6), a total of five mitochondrial lineages were found (Sanna et al. 2010). While this latter study confirmed that the genetic diversity of the invading population is low, its proper characterization is still a pending question, in particular regarding its nuclear component.

Therefore, the goal of this work was both to expand the coverage of mitochondrial markers from our previous study and to explore the genetic diversity of the Lessepsian population using a nuclear marker.

\section{Materials and methods}

DNA samples used in this study were from previous collections (Golani et al. 2007) and are summarized in Table 1 and Figure 1. We genotyped all samples for two mitochondrial markers, control region $(\mathrm{CR})$ and cytochrome oxidase 1 (CO1), and one nuclear marker, rhodopsin (ROD). The $\mathrm{CR}$ is commonly used for phylogeographic studies because it is assumed to have one of the fastest substitution rates in fish mitochondria (between $5 \%$ and $10 \%$ per million years), and is not under strong selective pressure (Domingues et al. 2005). Conversely, the CO1 maker is known to have slower substitution rates, thus supplementing the picture provided by the CR (Ward et al. 2005). Data for the CR were from a previous publication (Golani et al. 2007). The amplification of COI first used fish-specific primers VF2T1 and VR1dT1 (Ward et al. 2005). After obtaining some sequences, we designed a specific forward primer (COI FCO fwd 5 'GCTTAGCCAACCCGGTGCATTAC 3 ') that produced results more consistent with $F$. commersonii. Amplification of the nuclear rhodopsin marker followed published nested amplification protocols (Sevilla
Table 1. Genetic characteristics of Red Sea and Mediterranean populations of Fistularia commersonii based on combined mitochondrial markers and the nuclear marker. Number of samples $(n)$, number of haplotypes $(\mathrm{nH})$, molecular diversity $(\pi)$, and haplotype diversity (HD) are shown in columns from left to right (Data for each mitochondrial locus are provided in the Supplementary Table).

\begin{tabular}{lrrrr}
\hline Locality / Locus & $\mathrm{n}$ & $\mathrm{nH}$ & $\pi$ & $\mathrm{HD}$ \\
\hline CO1 + Control region & & & & \\
Red Sea & 45 & 42 & 20.065 & 0.997 \\
Eilat, Israel & 31 & 29 & 17.346 & 0.996 \\
Marsa Alam, Egypt & 14 & 13 & 21.231 & 0.989 \\
Mediterranean & 46 & 3 & 3.599 & 0.335 \\
Haifa, Israel & 12 & 1 & 0.000 & 0.000 \\
Jaffa, Israel & 2 & 1 & 0.000 & 0.000 \\
Rhodes, Greece & 20 & 3 & 2.842 & 0.358 \\
Lampedusa, Italy & 12 & 2 & 6.894 & 0.530 \\
Rhodopsin & & & & \\
Red Sea & 41 & 8 & 0.059 & 0.715 \\
Eilat, Israel & 26 & 8 & 0.052 & 0.779 \\
Marsa Alam, Egypt & 15 & 3 & 0.067 & 0.600 \\
Mediterranean Sea & 37 & 6 & 0.209 & 0.671 \\
Haifa, Israel & 11 & 4 & 0.218 & 0.746 \\
Rhodes, Greece & 15 & 4 & 0.105 & 0.543 \\
Lampedusa, Italy & 11 & 6 & 0.273 & 0.800 \\
\hline
\end{tabular}

et al. 2007), with RHO30F and RHO 319R for the first set of primers and Rho F2x and RhoR4n for the second set of primers. Number of haplotypes and haplotype diversity were calculated using the software ARLEQUIN (Excoffier \& Lischer 2010). Phylogenetic relationships between haplotypes were assessed using a Minimum Spanning Network, MSN or Haplotype Network (Excoffier \& Smouse 1994). Haplotype networks were generated in R using HaploNet in the APE package (Paradis et al. 2004) combined with pie diagrams of haplotype frequencies obtained with APE and ARLEQUIN (Excoffier \& Lischer 2010).

\section{Results}

We analyzed 96, 91 and 78 individuals for the CR, CO1 and ROD markers (Table 1). In all cases haplotype diversity was very high in the native populations of the Red Sea, averaging $0.997,0.707$ and 0.715 for CR, CO1 and ROD. In contrast, haplotype diversity was low in the invading Mediterranean population, with values of 0.259 , 0.085 and 0.335 (Table 1, Figure 2). The observed number of haplotypes followed previous trends, with greater numbers of haplotypes found in the Red Sea samples. There were over 40 haplotypes for the combined mitochondrial markers and eight for the nuclear marker for the Red Sea samples. In contrast, only two haplotypes were seen in the Mediterranean CR and CO1. Combining both markers yielded three haplotypes. The decrease in genetic diversity of the mitochondrial markers between the natural range and the Mediterranean was found to be highly significant (chi-square test, $\mathrm{p}<0.001$ ). The nuclear marker showed surprisingly high diversity levels, with six haplotypes observed in the Mediterranean, and the difference in nuclear diversity between the Red Sea and Mediterranean was not significant (chi-square test, $\mathrm{p}>0.1$ ). This finding was not an artifact of a larger sample number in the 


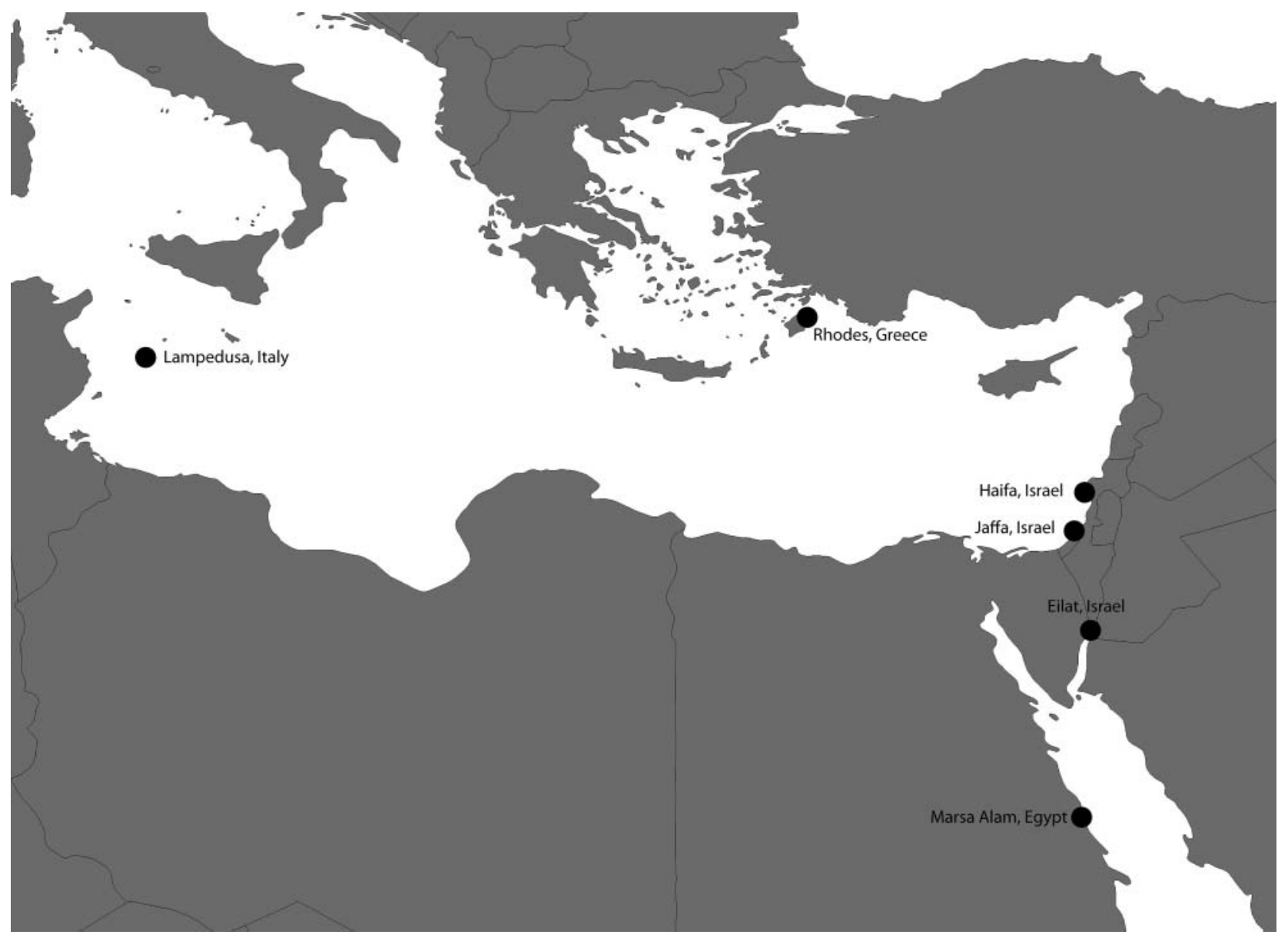

Figure 1. Collection localities for genetic samples of Fistularia commersonii

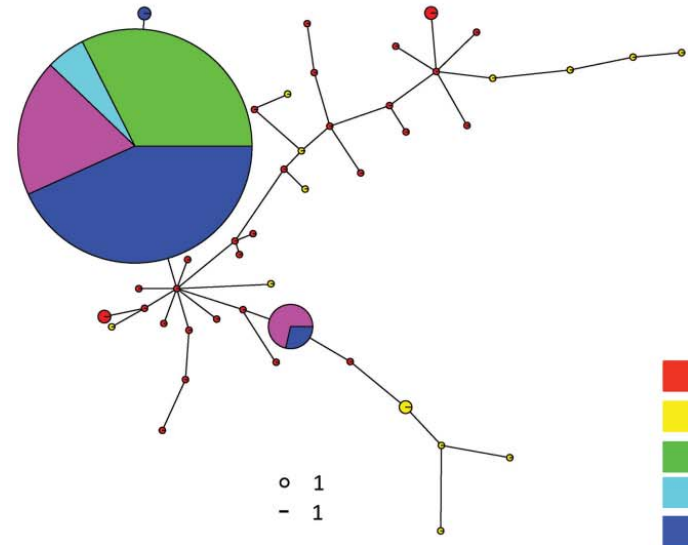

$m \operatorname{tDNA}=\mathrm{CR}+\mathrm{CO} 1$
Eilat, Israel Marsa Alam, Egypt Haifa, Israel Jaffa, Israel Rhodes, Greece Lampedusa, Italy Missing haplotype

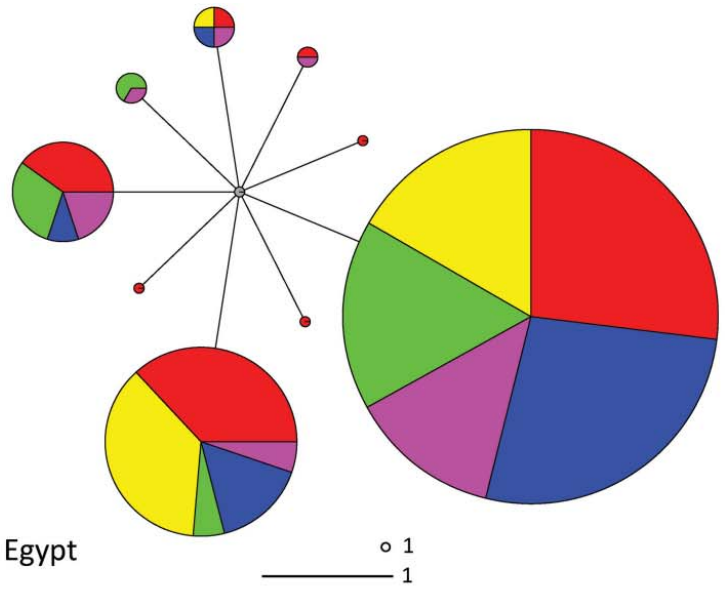

$\mathrm{nDNA}=\mathrm{ROD}$

Figure 2. Haplotype networks of Fistularia commersonii based on combined mitochondrial markers (CR and CO1) panel A and nuclear marker (ROD) panel B. Legend indicates the color of each sampling location, the size of a pie diagram for one individual and the size of a junction proportional to one substitution. The areas of the pie diagrams are proportional to the number of individuals within each pie. Haplotype networks for each mitochondrial marker are shown in Supplementary Figure 1. 
nuclear markers compared to the mitochondrial ones, as 46 samples were used to estimate mitochondrial haplotype numbers in the Mediterranean and only 36 samples were analyzed for the nuclear marker (Table 1).

\section{Discussion}

While it took $F$. commersonii 130 years to enter the Mediterranean Sea via the Suez Canal, it took only four years to disperse westward and colonize the central and eastern sectors of the basin. The species is now well established in the Mediterranean, with both juvenile and adult individuals commonly observed. Our finding of only three mitochondrial haplotypes in the Mediterranean while using a large number of individuals was consistent with previous work that showed very few haplotypes present there (Golani et al. 2007; Sanna et al. 2010). The detection of a strong bottleneck in Mediterranean populations of the bluespotted cornetfish, Fistularia commersonii, is consistent with the notion that the traverse of the Suez Canal has a strong stochastic component (Golani 1993).

In addition, we expanded the analysis in this study by using a nuclear marker. We found that the number of haplotypes decreased from the Red Sea to the Mediterranean (from eight to six), but this decrease was not statistically significant. This is in sharp contrast with the vast decrease in mitochondrial haplotype numbers, which decreases from 42 in the Red Sea to three in the Mediterranean.

Since mitochondrial DNA is maternally inherited, and the markers commonly used for phylogeographic studies (such as the control region) are usually subjected to low (if any) levels of natural selection, the use of nuclear markers may generally reveal two main patterns: (1) a difference between male and female population dynamics, and (2) evidence of selection (Avise 2004). In the case of the former, there may be sex-biased dispersal across the Suez Canal. Few female lineages may have migrated through the Canal, in comparison to much larger numbers of males. Evidence for sex-biased dispersal in $F$. commersonii could be properly assessed by conducting ecological studies in the field (Yue et al. 2012). While it is not possible to monitor the dispersal of these individuals through the Suez Canal, the spread of this species in the Mediterranean provides some interesting clues. For example, the sex ratio of invading individuals did not deviate significantly from 1:1 in the easternmost sectors of the Mediterranean (Bariche \& Kajajian 2012). In addition, the sequence of events noted in Mediterranean records does not provide evidence of a lower dispersal capability in female specimens. Indeed, in many of these cases, the recorded pioneer individuals were females (Azzurro et al. 2004; Karachle et al. 2004; Garibaldi \& Orsi Relini 2008). Alternatively, selection may play an important role in shaping the genetic composition of the invading population. In order to fully assess this scenario, additional data would be necessary. Genomic approaches could potentially provide a more comprehensive picture of the level of selection and potential for local adaptation experienced by the invading population (Hohenlohe et al. 2010).

\section{Conclusion}

While previous studies on Lessepsian species showed a surprising lack of bottlenecks, Fistularia commersonii provided an opportunity to investigate the earliest stages of biological invasions in the Mediterranean, and to monitor the evolution of genetic signatures in the future. There is increasing evidence that high propagule pressure may contribute to the elimination of founder effects in the majority of successful aquatic invasions (Roman \& Darling 2007). Our findings are particularly relevant given the increase in tropical species that have invaded the Eastern Mediterranean in recent years (Golani 2010). Closely monitoring their advances will enable us to replicate the current study and determine whether the results obtained with the bluespotted cornetfish correspond to a general pattern of Lessepsian invasions.

\section{Acknowledgements}

This manuscript is dedicated to the memory of our colleague Professor Uzi Ritte.

\section{Funding}

The work was funded by an Initiative for Maximizing Student Development/National Institute of Health (IMSD/NIH) grant.

\section{Supplemental data}

Supplemental data can be accessed here.

\section{References}

Avise JC. 2004. Molecular Markers, Natural History, and Evolution. Sunderland, MA: Sinauer.

Azzurro E, Golani D, Bucciarelli G, Bernardi G. 2006. Genetics of the early stages of invasion of the Lessepsian rabbitfish Siganus luridus. J Exp Mar Biol Ecol. 333:190-201.

Azzurro E, Pizzicori P, Andaloro F. 2004. First record of Fistularia commersonii (Fistularidae) from the central Mediterranean. Cybium. 28:72-74.

Azzurro E, Soto S, Garofalo G, Maynou F. 2012. Fistularia commersonii in the Mediterranean Sea: invasion history and distribution modeling based on presence-only records. Biol Invasions. 15:977-990.

Bariche M, Kajajian A. 2012. Population structure of the bluespotted cornetfish Fistularia commersonii (Osteichthyes: Fistulariidae) in the eastern Mediterranean Sea. J Biol ResThessalon. 17:74-80.

Bucciarelli G, Golani D, Bernardi G. 2002. Genetic cryptic species as biological invaders: the case of a Lessepsian fish migrant, the hardyhead silverside Atherinomorus lacunosus. Science. 273:143-149.

Deidun A, Germanà A. 2011. On the increasing occurrence of the Bluespotted Cornetfish Fistularia commersonii (Rüppel, 1838 ) in the Central Mediterranean (Osteichthyes, Fistulariidae). Biodivers J. 2:19-26.

Domingues VS, Bucciarelli G, Almada VC, Bernardi G. 2005. Historical colonization and demography of the Mediterranean damselfish, Chromis chromis. Mol Ecol. 14:4051-63.

Dulčić J, Scordella G, Guidetti P. 2007. On the record of the Lessepsian migrant Fistularia commersonii (Rüppell, 1835) from the Adriatic Sea. J Appl Ichthyol. 24:101-102.

Excoffier L, Lischer HEL. 2010. Arlequin suite ver 3.5: a new series of programs to perform population genetics analyses under Linux and Windows. Mol Ecol Resour. 10:564-7. 
Excoffier L, Smouse PE. 1994. Using allele frequencies and geographic subdivision to reconstruct gene trees within a species: molecular variance parsimony. Genetics. 136: 343-59.

Fricke R, Golani D, Appelbaum-Golani B. 2012. First record of the Indian Ocean anchovy Stolephorus insularis Hardenberg, 1933 (Clupeiformes: Engraulidae) in the Mediterranean. BioInvasions Rec. 1:303-306.

Garibaldi F, Orsi Relini L. 2008. Record of the bluespotted cornetfish Fistularia commersonii Rüppell, 1838 in the Ligurian Sea (NW Mediterranean). Aq Inv. 3:471-474.

Golani D. 1993. The sandy shore of the Red Sea-launching pad for Lessepsian (Suez Canal) migrant fish colonizers of the eastern Mediterranean. J Biogeogr. 20:579-585.

Golani D. 2000. First record of the bluespotted cornetfish from the Mediterranean Sea. J Fish Biol. 56:1545-1547.

Golani D. 2010. Colonization of the Mediterranean by Red Sea fishes via the Suez Canal - Lessepsian migration. In: Golani D, Appelbaum-Golani B editors. Fish invasions of the Mediterranean Sea: Change and renewal. Sofia: Pensoft Publishers; pp. $145-188$.

Golani D, Azzurro E, Corsini-Foka M, Falautano M, Andaloro F, Bernardi G. 2007. Genetic bottlenecks and successful biological invasions: the case of a recent Lessepsian migrant. Biology letters, 3:541-5.

Golani D, Ritte U. 1999. Genetic relationship in goatfishes (Mullidae: Perciformes) of the Red Sea and the Mediterranean, with remarks on Suez Canal migrants*. Sci Mar. 63:129-135.

Hassan M, Bonhomme F. 2005. No reduction in neutral variability of mitochondrial and nuclear genes for a Lessepsian migrant, Upeneus moluccensis. J Fish Biol. 66:865-870.

Hassan M, Harmelin-Vivien M, Bonhomme F. 2003. Lessepsian invasion without bottleneck: example of two rabbitfish species (Siganus rivulatus and Siganus luridus). J Exp Mar Biol Ecol. 291:219-232.

Hohenlohe PA, Phillips PC, Cresko WA. 2010. Using population genomics to detect selection in natural populations: Key concepts and methodological considerations. Int J Plant Sci. 171:1059-1071.
Karachle PK, Triantaphyllidis C, Stergiou KI. 2004. Bluespotted cornetfish, Fistularia commersonii Ruppell, 1838: A Lessepsian sprinter. Acta Ichthyol Piscat. 34:103-108.

Merella P, Casu M, Garippa G, Pais A. 2010. Lessepsian fish migration: genetic bottlenecks and parasitological evidence. J Biogeogr. 37:975-978.

Paradis E, Claude J, Strimmer K. 2004. APE: Analyses of Phylogenetics and Evolution in $\mathrm{R}$ language. Bioinformatics. 20:289-290.

Pirkenseer C. 2012. Records of four non-indigenous marine species, south of Koroni (Messiniakos Gulf, Peloponnese, Greece). BioInvasions Rec. 1:87-93.

Roman J, Darling J a. 2007. Paradox lost: genetic diversity and the success of aquatic invasions. Trends ecol evol. 22:454-64.

Sala E, Kizilkaya Z, Yildirim D, Ballesteros E. 2011. Alien marine fishes deplete algal biomass in the Eastern Mediterranean. PloS one. 6:e17356.

Sanchez-Tocino L, Hidalgo Puertas F, Pontes M. 2007. First record of Fistularia commersonii Ruppell, 1838 (Osteichtyes: Fistulariidae) in Mediterranean waters of the Iberian Peninsula. Zoologia Baetica. 18:79-84.

Sanna D, Merella P, Lai T, Farjallah S, Francalacci P, Curini-Galletti M, Pais A, Casu M. 2010. Combined analysis of four mitochondrial regions allowed the detection of several matrilineal lineages of the lessepsian fish Fistularia commersonii in the Mediterranean Sea. J Mar Biol Assoc UK. 91:1289-1293

Sax DF, Brown JH, White EP, Gaines SD. 2005. The Dynamics of Species Invasions (DF Sax, JJ Stachowicz, SD Gaines, Eds,). The Dynamics of Species Invasions; pp. 447-465.

Sevilla RG et al. 2007. Primers and polymerase chain reaction conditions for DNA barcoding teleost fish based on the mitochondrial cytochrome $\mathrm{b}$ and nuclear rhodopsin genes. Mol EcolNotes. 7:730-734.

Ward RD, Zemlak TS, Innes BH, Last PR, Hebert PDN. 2005. DNA barcoding Australia's fish species. Philos t Roy Soc B. 360:1847-57.

Yue GH, Xia JH, Liu F, Lin G. 2012. Evidence for female-biased dispersal in the protandrous hermaphroditic Asian Seabass, Lates calcarifer. PloS one. 7:e37976. 